\title{
LOS SIGNOS OVALES PALEOLÍTICOS DE LA CUEVA DE EL CASTILLO (PUENTE VIESGO, CANTABRIA): DATOS PARA UN PLANTEAMIENTO INTERPRETATIVO Y SU ATRIBUCIÓN CRONO-CULTURAL
}

\author{
PALEOLITHIC OVAL SIGNS FROM EL CASTILLO CAVE (PUENTE VIESGO, CANTABRIA): \\ DATA FOR INTERPRETIVE APPROACH AND CHRONO-CULTURAL ATTRIBUTION
}

\author{
ALBERTO MINGO ÁLVAREZ*
}

\begin{abstract}
Resumen: En el interior de la cueva de El Castillo (Puente Viesgo, Cantabria) se documentan una gran cantidad de expresiones gráficas paleolíticas que además manifiestan una notable diversidad formal. Entre las categorías temáticas más destacadas de esta cavidad se hallan "los signos". En este trabajo se presentan los resultados del análisis morfológico, técnico, contextual y topográfico de los signos con forma oval. A partir de estos datos se plantea una hipótesis interpretativa de su significado y una aproximación a su atribución crono-cultural. Palabras clave: cueva de El Castillo, Paleolítico, signos ovales, hipótesis interpretativa, atribución crono-cultural.
\end{abstract}

\section{INTRODUCCIÓN}

La definición de signo paleolítico dentro de nuestra disciplina ha reflejado, a lo largo de todos estos años de investigación, los modelos teóricos aplicados para proferir interpretaciones del fenómeno gráfico pleistocénico. Desde un primer momento, los especialistas de la Prehistoria localizaron figuras, tanto en soporte mobiliar como parietal, que no podían ser asimilables morfológicamente a animales cuaternarios, motivos antropomorfos o a cualquier otro tipo temático figurativo reconocido. Así, los signos paleolíticos fueron entendidos como "ciertas figuras de forma geométrica que

\footnotetext{
* Dpto. Prehistoria y Arqueología. UNED. C/ Senda del Rey, 7; 28040 - Madrid. E-mail:amingo@geo.uned.es
}

Summary: Cueva de El Castillo (Puente Viesgo, Cantabria) contains a great quantity of palaeolithic images which in addition shows a significant formal diversity. "The signs" make up one of the most outstanding thematic categories of the cave. In this paper, we present the results derived from the morphological, technical, contextual and topographical analysis of the oval signs. From this data we put forward an interpretative hypothesis of their significance and we bring up an approach of their chrono-cultural attribution.

Key words: cueva de El Castillo, Palaeolithic, oval signs, interpretative hipothesis, chrono-cultural attribution.

contrastan con las imágenes naturalistas habituales" (Capitan y Breuil 1902; citado en Sauvet 1993: 219).

Los signos conforman probablemente la categoría más compleja de la temática gráfica paleolítica. Estamos de acuerdo con R. Layton (1987: 219-220) cuando apunta que "se trata de una categoría residual, subjetivamente definida, que se distingue por nuestra incapacidad de saber con certeza lo que estas imágenes significan". La consideración de que "bajo esta apelación genérica (de signos) se hallan formas geométricas, representaciones no figurativas indeterminadas $\mathrm{y}$, a veces, incluso elementos de decoración" formulada por D. Vialou (1983: 597) es un axioma.

Un signo paleolítico intencional sería, para nosotros, toda aquella representación o imagen de un objeto (objeto, elemento, fenómeno, idea o acción material) 
que alcanza un grado de esquematización, geometrización, etc. tal que no podemos reconocer en ella, desde nuestra perspectiva, el objeto origen que representa o sustituye. A pesar de que en nuestra disciplina, como bien cita M. R. González Morales (1994: 297), se juzga que una representación es un signo cuando no podemos identificarla con certeza a formas animales o antropomorfas, creemos que no habría que incluir a las "manos" dentro de la categoría "signos" ya que son, al igual que la fauna y los antropomorfos, imágenes perfectamente reconocibles. La tipología de signos es tan extensa que casi convendría decir que todo lo que no entra dentro de las categorías de animales (incluyendo los fantásticos) y de antropomorfos se ha contemplado como un signo.

\section{ALGUNAS CONSIDERACIONES SOBRE LOS VESTIGIOS ARQUEOLÓGICOS Y EXPRESIVOS DE LA CUEVA DE EL CASTILLO}

La cueva de El Castillo, localizada en Puente Viesgo (Cantabria), se abre a media ladera de la vertiente noreste del monte del mismo nombre, a unos 190 metros sobre el nivel del mar. El monte forma parte de la Sierra del Dobra en sus estribaciones orientales, levantándose en la orilla izquierda del río Pas. (Fig. 1)

La amplitud y buena habitabilidad del vestíbulo de esta caverna y el emplazamiento excepcional del monte donde se ubica (tanto por el control del territorio como por la cercanía y facilidad de acceso a múltiples y complementarias posibilidades ecológicas alimenticias) provocaron un recurrente y significativo poblamiento a lo largo de extensas fases crono-culturales del Paleolítico medio y superior como bien se observa en los estratos arqueológicos. El yacimiento paleolítico de la cueva de El Castillo se ha erigido en uno de los referenciales de Europa y seguramente del mundo. Su potente estratigrafía se traduce en una sucesión de capas, casi sorprendentemente horizontales, donde se alternan las estériles con las arqueológicamente fértiles. Se advierten 26 niveles, constatándose desde un Achelense final y un Paleolítico medio antiguo hasta una capa sedimentaria atribuida a la Edad del Bronce, pasando por todos los periodos culturales del Paleolítico superior. En total el registro arqueológico abarcaría un lapso cronológico que comenzaría más allá de 100.000 años antes del presente y finalizaría hace unos 3000-4000 años.

Las expresiones gráficas paleolíticas que contiene esta cavidad son muy numerosas y heterogéneas desde casi todos los planos que permite su estudio: técnico, temático, morfológico, estilístico, contextual, topográfico, etc. Esta variedad y cantidad de variables determinan que la gran mayoría de los investigadores, excepción hecha de los estructuralistas (principalmente A. Leroi-Gourhan), reconozcan que se trata de un "santuario" donde se constatan diferentes fases cronológicas en la realización de sus representaciones. La variedad percibida, además de la importancia $\mathrm{y}$, en ocasiones, singularidad que albergan muchos de sus motivos conduce a su aceptación como una de las principales cuevas con arte paleolítico en el área cantábrica. (Fig. 2)

Un recuento reciente de las figuras publicadas hasta el momento en la cavidad ha permitido cuantificar "más de 240 representaciones: 56 manos negativas, 54 ciervas, 26 caballos, 24 bisontes, 18 ciervos, 10 cabras, 6 uros, 3 rebecos, 2 máscaras, 1 antropomorfo, y 1 proboscídeo, así como 5 cérvidos, 13 bóvidos, 5 cápridos y 22 cuadrúpedos indiferenciables" (González Sainz et al. 2003: 106). En cuanto a las representaciones no figurativas (signos), la tesis doctoral que defendimos en julio de 2007 titulada "El estudio de los signos rupestres en el arte paleolitico: la cueva de El Castillo (Puente Viesgo, Cantabria)" desveló la existencia de 432 discos soplados, 18 de ellos aislados y 63 seriaciones, desde un número de 2 hasta de 36 discos; 4 signos claviformes; 5 signos "campaniformes"; 17 signos ovales; y 27 signos rectangulares. Los trazos pintados y líneas grabadas alcanzan un número superior a las 240 unidades gráficas mientras que se han documentado 48 realizadas por puntos, entre ellos son reseñables la aparición de 19 puntos aislados y 17 con grupos de más de 5 puntos. Finalmente se han cuantificado 42 manchas $^{1}$.

\section{LOS SIGNOS OVALES DE EL CASTILLO. ANÁLISIS MORFOLÓGICO, TÉCNICO, CONTEXTUAL Y TOPOGRÁFICO}

La cueva de El Castillo a tenor de sus características topográficas ha sido dividida en cuatro áreas (Mingo 2004). Éstas albergan espacios diferenciados y particulares que han de configurarse en sub-áreas (fig. 3). La concentración de unidades gráficas en emplazamientos muy localizados permitió definir, a su vez, sectores dentro de éstas zonas.

1. Mingo, A. (2007): El estudio de los signos rupestres en el arte paleolitico: la cueva de El Castillo (Puente Viesgo, Cantabria). Tesis Doctoral Inédita. UNED. Madrid. 
Figura 1. Mapa de situación de la cueva de El Castillo.
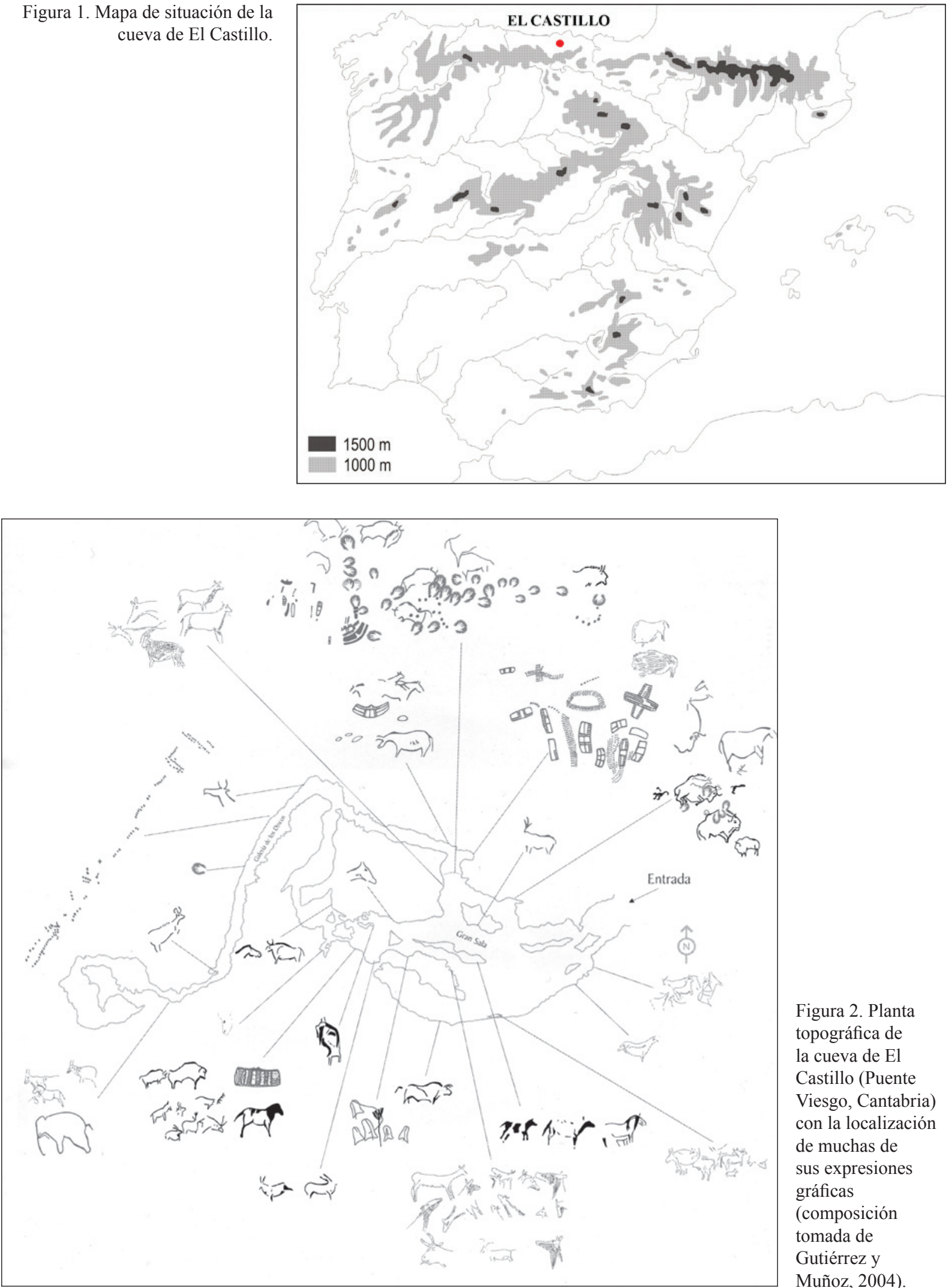

Figura 2. Planta topográfica de la cueva de El Castillo (Puente Viesgo, Cantabria) con la localización de muchas de sus expresiones gráficas (composición tomada de Gutiérrez y Muñoz, 2004).

ISSN: 1133-4525 ISSN-e: 2255-3924 


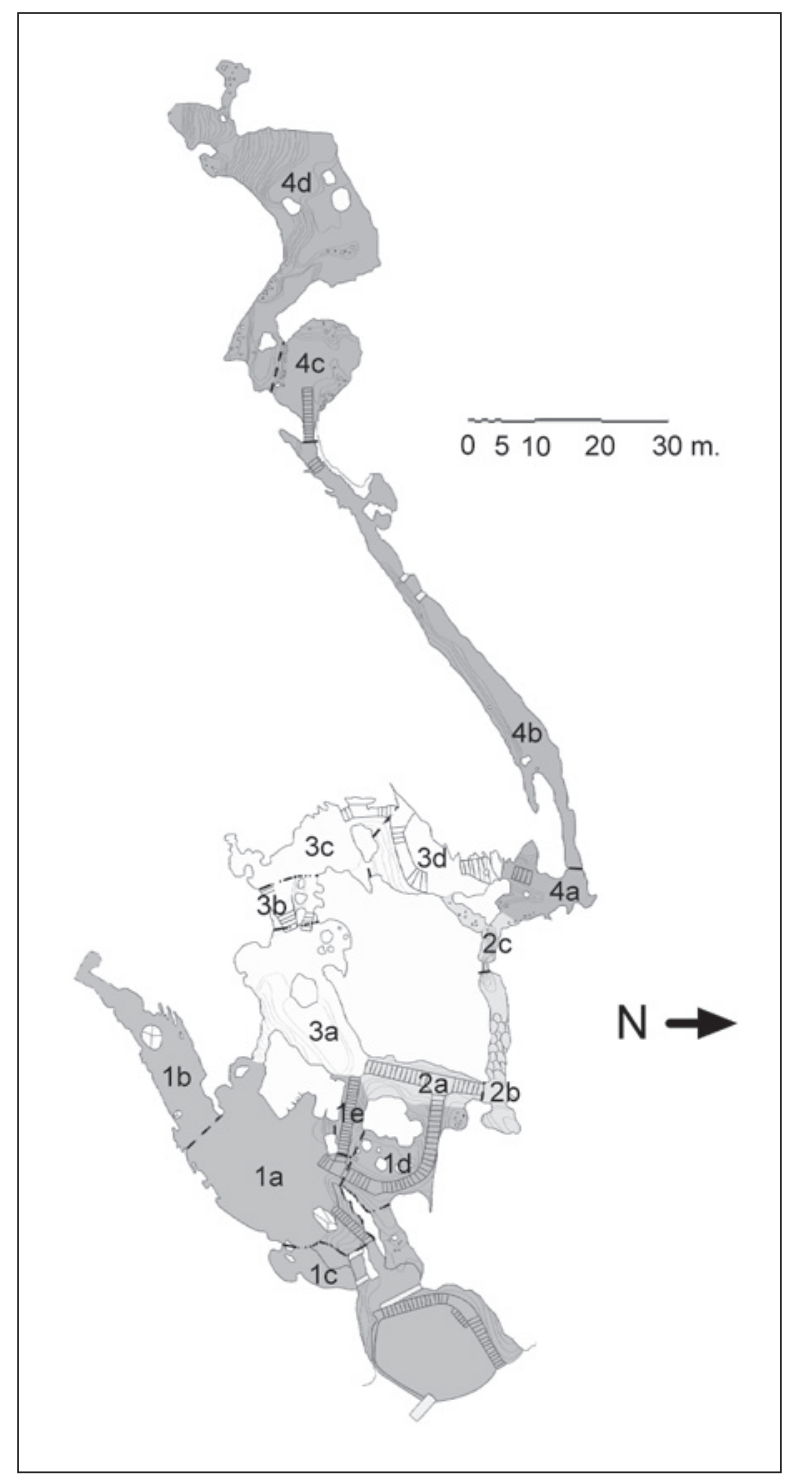

Figura 3. División topográfica de la cueva de El Castillo en áreas (diversos tonos de grises y blancos) y sub-áreas.

La práctica totalidad de los signos ovales $(\mathrm{N}=16)$ se localizan en el Área 2 (Galería de las Manos), tan solo uno se ubica en el Área 4 (Galería de los Discos). Las subáreas en que fue delimitada el Área 2 fueron las siguientes:

2.a: abarca completamente el Panel de las Manos, la zona previa (al sur) y el tramo de galería (en el que se localiza parte del citado panel) hasta que cambia su orientación sur-norte.

2.b: segundo tramo de la Galería de las Manos. Desde el cambio de orientación de ésta, ahora este-oeste (incluyendo un pequeño camarín al lado este), hasta su "estrangulamiento" (estrechamiento y colmatación). 2.c: continuación por el oeste de dicha galería hasta que alcanza la Galería de los Discos.

El criterio seguido en esta división se ajusta al sentido de la progresión hacia el interior. El Área 4, por su parte, corresponde a los lugares finales del complejo kárstico, y su sub-división quedo así:

4.a: emplazamiento donde confluyen la Galería de las Manos (Área 2) y la Cuarta Sala (Área 3); y el principio de la Galería de los Discos. Todavía este espacio no presenta un elevado techo y es más amplio que la siguiente sub-área.

4.b: se ajusta a todo el corredor conocido como la Galería de los Discos hasta llegar a la Sala Final. Este tránsito comparte unos mismos rasgos endokársticos.

4.c: la mal llamada Sala Final y que, en verdad, es la penúltima sala.

4.d: el último pasaje y la verdadera última sala donde la cueva se ciega en la actualidad.

A pesar de que el desarrollo de clasificaciones morfológicas ha supuesto un indudable avance en la investigación, no debemos olvidar que, en último término, la conformación de tipologías sufre la existencia de componentes arbitrarios y subjetivos propios de los especialistas. En este sentido, estamos plenamente de acuerdo con G. Sauvet cuando apunta que "decidir que dos grafismos tiene unos caracteres morfológicos lo suficientemente comunes para ser considerados como variantes (y designarlos bajo tal nombre) es ya una operación subjetiva...[...]...Nombrar es clasificar, y clasificar es elegir según unos criterios que son en parte arbitrarios" (Sauvet 1993: 223). El uso y aplicación de las clasificaciones es, en cualquier caso, una herramienta básica para la comprensión y mejor conocimiento de estas imágenes dentro de los conjuntos iconográficos paleolíticos.

Ciñéndonos a los signos objeto de nuestro estudio vemos que su forma básica es la ovalada (fig. 4). No obstante, se atisban dos tendencias dentro de ésta: una morfología oval redondeada (tipos 1 y 2) y otra oval sub-triangular (tipos 3, 4, 5 y 6). El tipo 2 supone la adición de un trazo / línea horizontal a la zona superior de la forma base oval redondeada. El tipo 4 es un oval sub-triangular pero presenta en su extremo izquierdo un trazo / línea seudo-vertical que rompe la inflexión curva típica de esta parte del signo. El tipo 5 exhibe un trazo / línea largo ascendente a la derecha que cruza el signo y que en su extremo superior converge con un trazo / línea corto seudo-horizontal. El tipo 6 repite una estructura semejante al anterior, aunque se añaden dos 


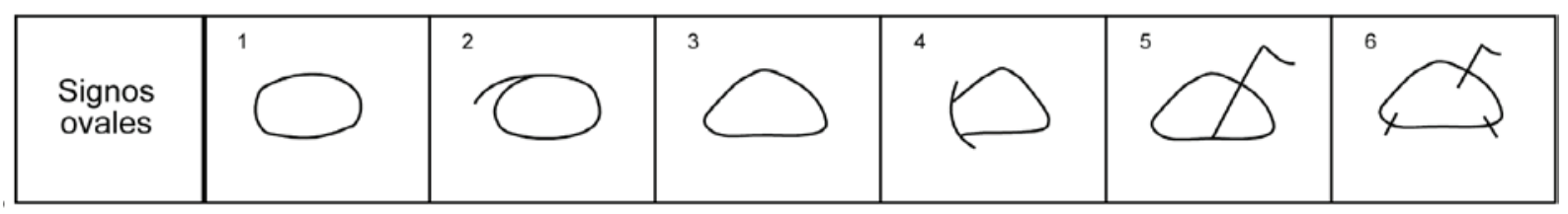

Figura 4. Tipología de los signos ovales localizados en la cueva de El Castillo.

trazos / líneas cortos oblicuos en los extremos inferiores del signo y el trazo oblicuo que le cruza se reduce considerablemente.

Las dos formas base de los signos ovales (tipos 1 y 3 ) son las que cuentan con mayor representación (Tabla 1). Se aprecia un claro predominio del tipo $3(\mathrm{~N}=10)$ que coincide con el signo oval sub-triangular. Los restantes tipos $(2,4,5$ y 6$)$ reflejan el desarrollo de las formas básicas y su presencia es tan reducida que no supera la unidad. Los tipos 2 y 4 exhiben una morfología que podría sugerir no tanto una diferenciación clara con respecto a las formas base sino quizá apuntar a modificaciones no intencionadas producidas en el proceso de ejecución de las expresiones. Los tipos 5 y 6 , por el contrario, sí patentizan una variación de las formas bases por adición de trazos. Es muy significativa la semejanza observada en ambos tipos, exhibiendo una forma subtriangular sobre la que se disponen dos trazos convergentes con la misma orientación y situación. El añadido de dos trazos cortos oblicuos distingue a un tipo de otro.

Tabla 1: distribución numérica de los tipos definidos para el grupo de signos ovales.

\begin{tabular}{|c|c|}
\hline Signos ovales & N \\
\hline Tipo 1 & 3 \\
\hline Tipo 2 & 1 \\
\hline Tipo 3 & 10 \\
\hline Tipo 4 & 1 \\
\hline Tipo 5 & 1 \\
\hline Tipo 6 & 1 \\
\hline Total & 17 \\
\hline
\end{tabular}

En cuanto a la técnica empleada en su ejecución observamos que en su conjunto fueron realizados en pintura. La mayoría de ellos (casi dos tercios) con pigmento rojo (tipos 1, 2, 3, 4 y 5) y el resto en ocre amarillento / pardo (un tercio) (tipos 1, 3 y 6). Los ovales son la categoría de signos de El Castillo donde en mayor medida se atestigua el uso del ocre amarillento / pardo. La información técnica nos está indicando que no existe un vínculo entre forma (signo oval) y un solo color, sino que, aún predominando el rojo, hay una relación indistinta con el rojo y el amarillo / pardo.

Como vimos al inicio de este apartado la situación topográfica de estos signos es tremendamente homogénea y concreta. 15 de 17 cuantificados se documentan en la sub-área 2.b (segundo tramo de la Galería de las Manos) (fig. 5). De los dos restantes uno aparece en la sub-área 2.a (se encuentra sobre la pared, muy cercano al inicio de la sub-área 2.b, superpuesto a una mano en negativo y en asociación contextual próxima con series de puntos) y el otro en la sub-área 4.b (localizado en la pared de un pequeño divertículo abierto en la pared norte, rodeado de restos de pigmento y algún trazo corto) (tipo 5) (fig. 6).

7 signos ovales se ven influenciados en su localización por la existencia de fisuras y grietas naturales. $5 \mathrm{se}$ presentan sobre techo y el resto en pared. Sus dimensiones oscilan entre los 34 y los 10 centímetros de anchura y los 15 y los 5 centímetros de altura.

Al inicio de la Galería de las Manos (sub-área 2.b) se distinguen sobre el techo 3 signos ovales adyacentes en pintura roja asociados con un punto aislado. Igualmente en el inicio de esta zona pero en la pared norte se dispone otro trío ( 2 en ocre amarillento y 1 en rojo) (lámina I y figuras 7, 8 y 9). Uno de los signos en ocre amarillento además de tener unos trazos asociados (tipo 6) se encuentra infrapuesto a un grupo de líneas grabadas (fig. 7). A escasos 2 metros del anterior grupo se aprecian otros dos signos ovales en rojo, sobre pared, que se encuentran entre un équido en rojo con trazos en su flanco y un signo rectangular con subdivisión interna y apéndice en su lado superior (Lámina II). A su izquierda se halla en contexto inmediato un trazo en horizontal. En la pared de enfrente se advierte un nuevo trío de ovales, 2 en rojo y 1 en ocre amarillento (Lámina III). Sobre el techo de esta posición se ubican 2 signos ovales en rojo: uno con unas digitaciones en rojo a su derecha inmediata (tipo 4) y otro dibujado sobre una arista del techo en contexto con la figura pintada de un caballo (en ocre amarillento), una cierva (en rojo), un punto rojo y varios trazos en rojo del interior del caballo. Por último, hallamos otros 2 signos ovales en ocre amarillento sobre la pared, avanzando unos 7 metros hacia el interior 


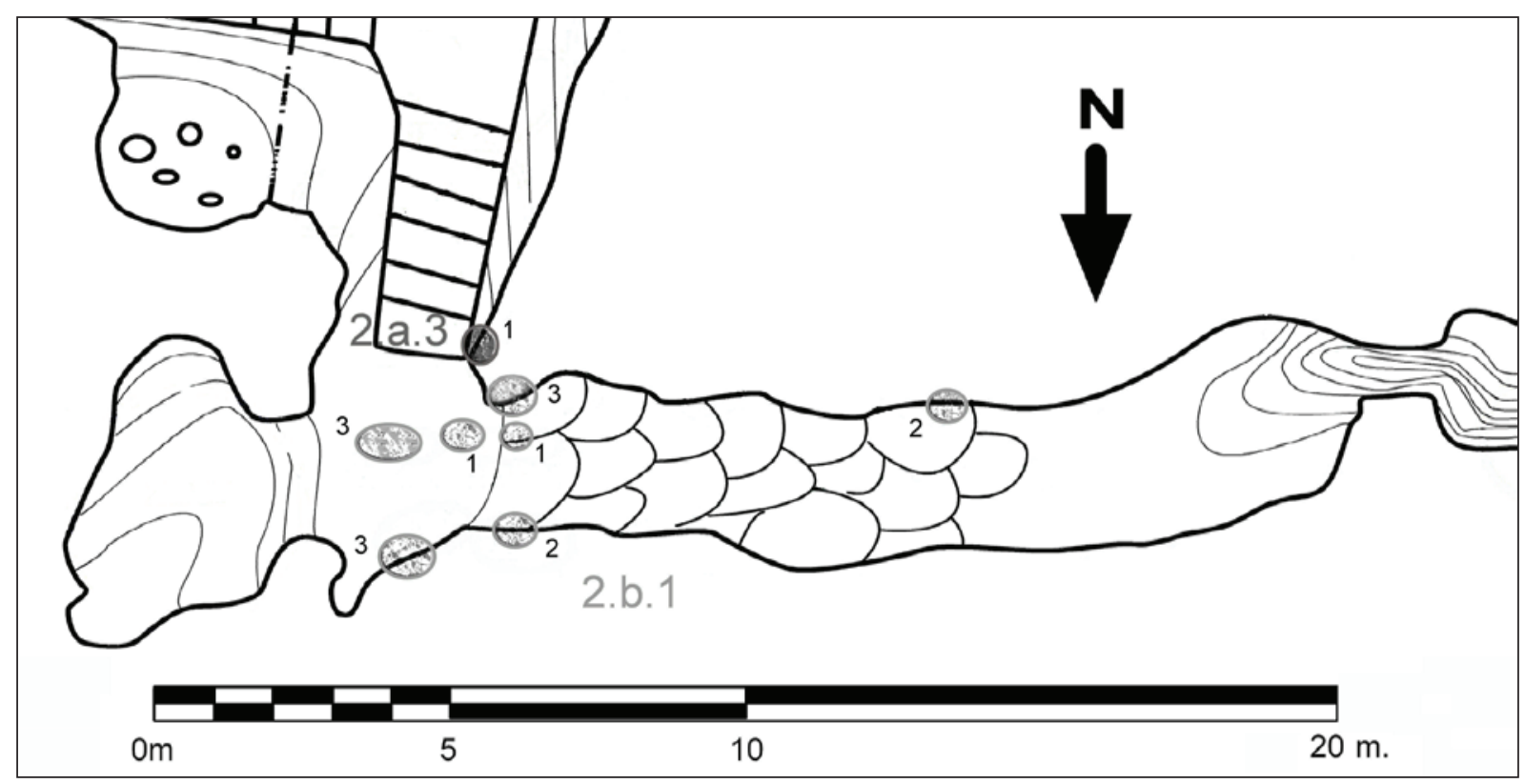

Figura 5. Localización de los signos ovales en el Área 2. En círculo gris oscuro aparece el oval presente en el sector 2.a.3 y en círculos grises claros los dispuestos en el sector 2.b.1. Los números próximos a los círculos indican la cantidad de signos ovales presentes en cada uno de ellos.

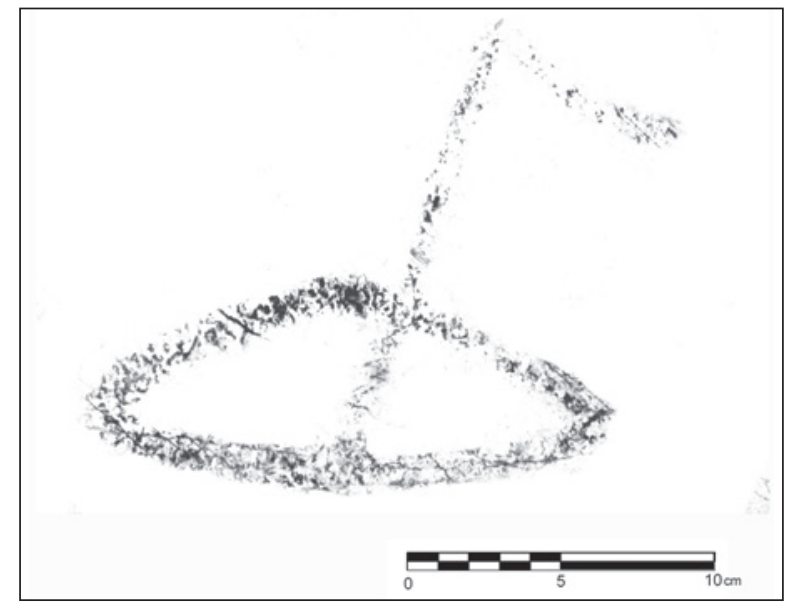

Figura 6. Calco del signo oval del tipo 5, localizado en la sub-área 4.b.

de la galería desde la localización de los anteriores. Se encuentran en asociación contextual entre ellos.

Amén de una evidente e intencional elección topográfica de este tipo de signos, constatamos a través del análisis contextual una tendencia a la representación en grupo de los mismos (tres tríos y dos pares) y un uso casi indistinto de la pintura roja y ocre amarillenta (parda) en su realización (en dos de los tríos se alterna

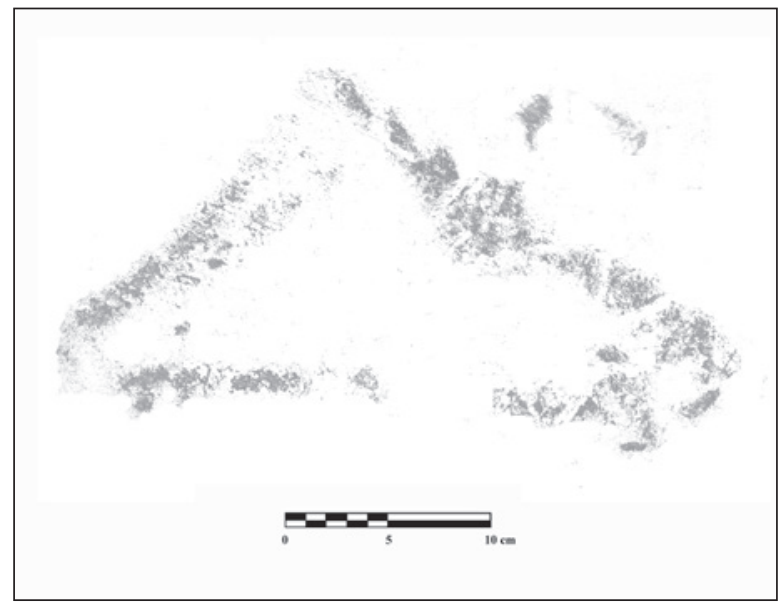

Figura 7. Calco del signo oval en ocre amarillento del tipo 6, localizado en la sub-área 2.b. Situado arriba y a la izquierda en la Lámina 1.

la gama cromática, uno de los pares se hizo en rojo y el otro en ocre amarillento).

\section{APROXIMACIÓN A SU INTERPRETACIÓN}

Los primeros investigadores del arte presente en la cavidad del Castillo: H. Alcalde del Río, H. Breuil 


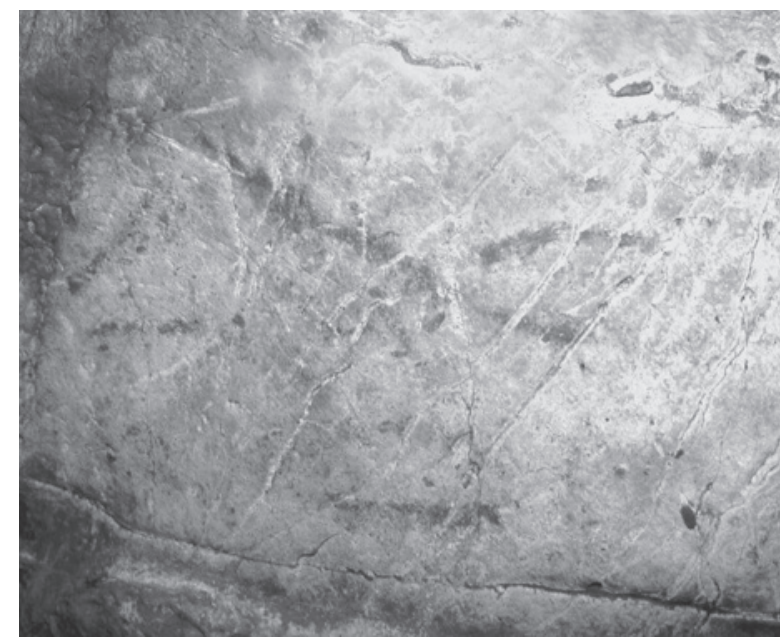

Lámina I. Fotografía de contexto de un trío de signos ovales, dos en ocre amarillento (pardo) y 1 en rojo, emplazados en la pared norte de la sub-área 2.b. Los tres signos exhiben una deficiente conservación al presentar un pigmento muy desvaído.

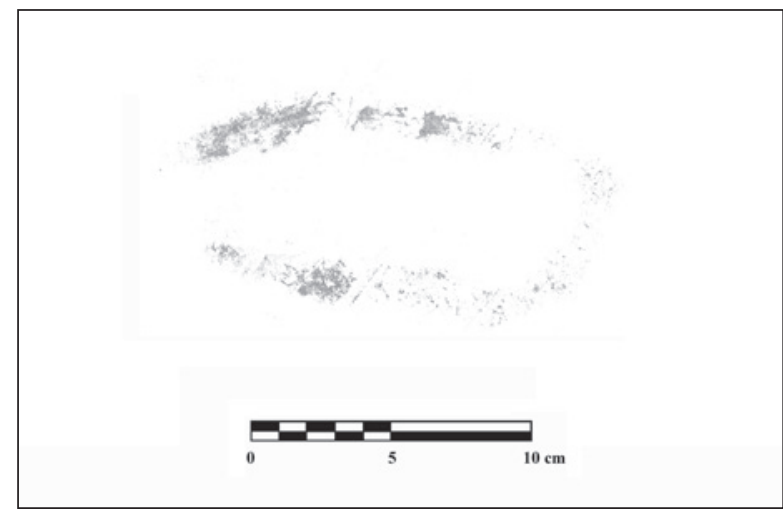

Figura 8. Calco del signo oval en ocre amarillento, localizado en la sub-área 2.b. Situado en la parte central y a la derecha en la Lámina 1.

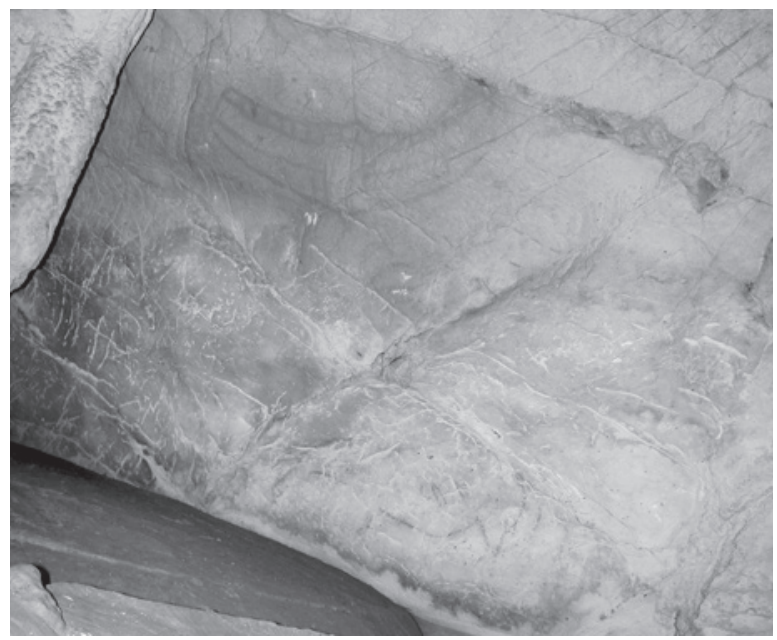

Lámina II. Fotografía de contexto de dos signos ovales en rojo. Se hallan por debajo del signo rectangular con subdivisión interna y arriba de del équido, en la pared norte de la sub-área 2.b.

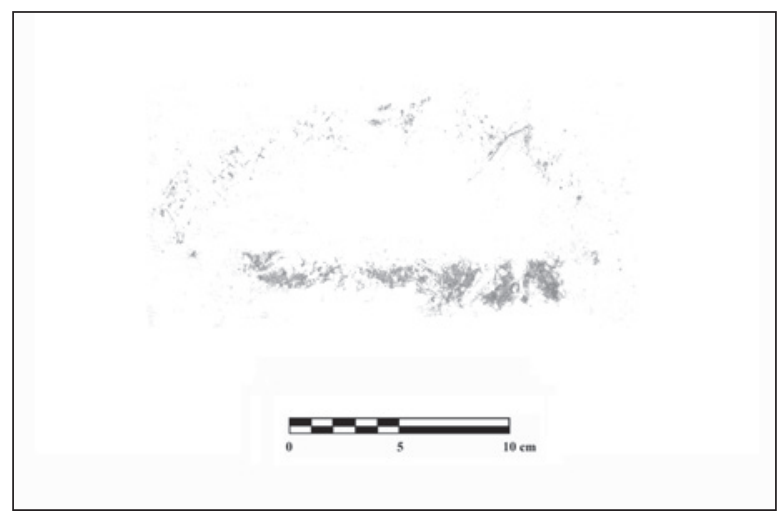

Figura 9. Calco del signo oval en rojo, localizado en la sub-área 2.b. Situado en la parte baja en la Lámina 1.
Lámina III. Fotografía de un signo oval subtriangular en rojo. Se localiza en la pared sur de la sub-área $2 . b$ en asociación con otros dos ovales con pigmento muy deteriorado. Exhibe una deficiente conservación en su mitad derecha.

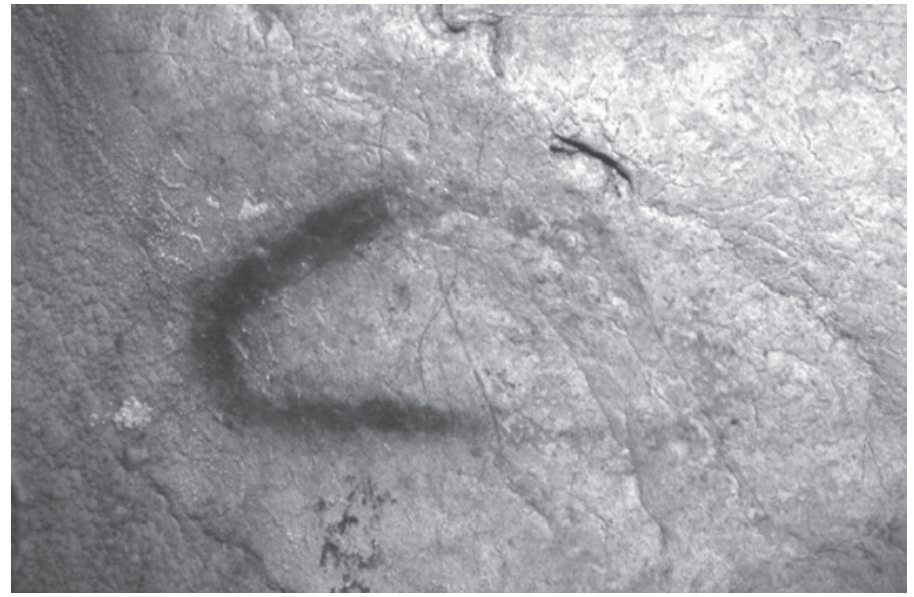




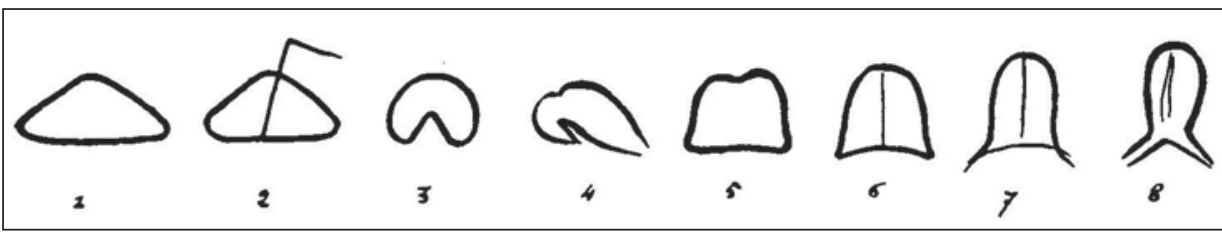

Figura 10. Serie de variantes de supuestos signos "tectiformes", según H. Alcalde del Río et al. (1911).

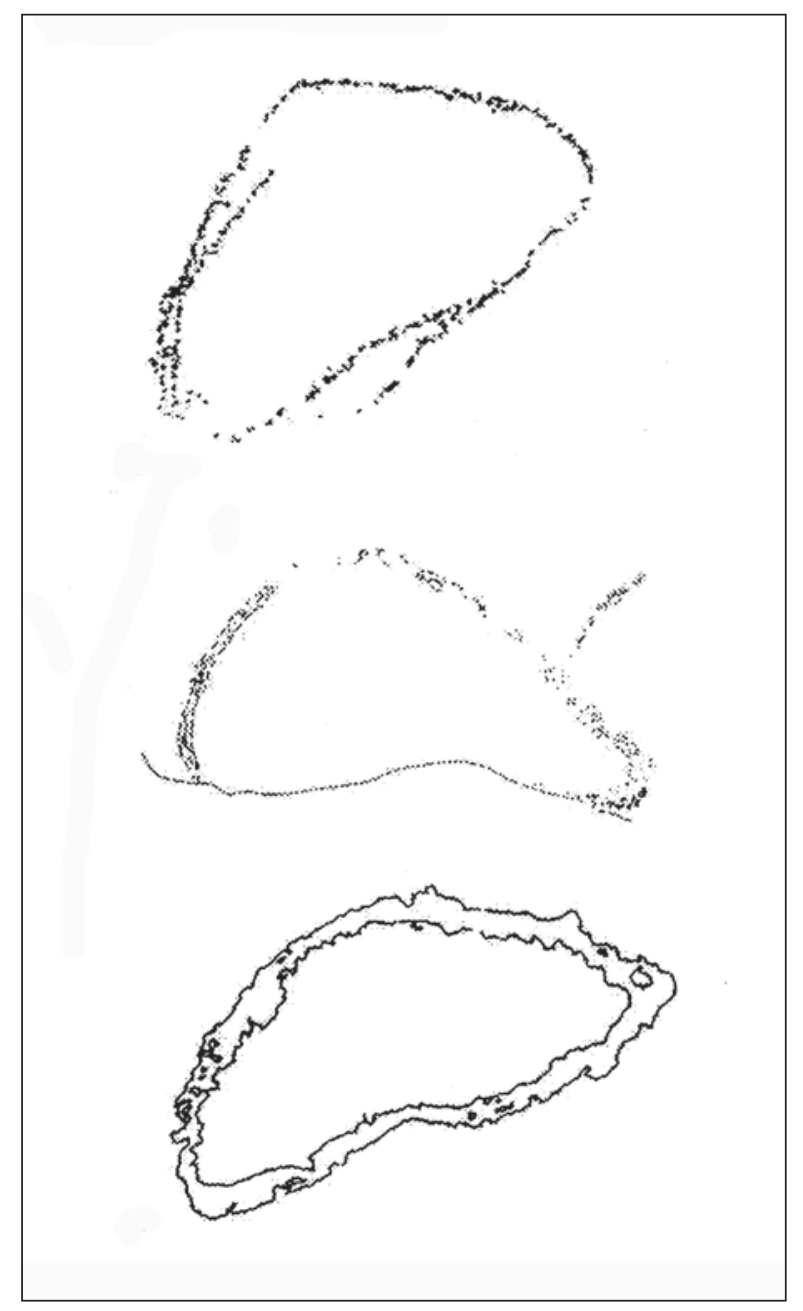

Figura 11. Signos ovales de la cueva de Mayenne-Sciences (Thorigné-en-Charnie, Mayenne, France).

y L. Sierra, incluyeron a los signos ovales dentro del grupo de los "tectifomes y escutiformes primitivos" realizados en la cueva (Alcalde del Río et al. 1911: 179), junto con los signos "campaniformes" y un signo vulvar (fig. 10).

En un contraste de pareceres con R. Pigeaud, durante la celebración del Congreso de la UISPP de Lieja (Bélgica), en torno a los signos ovales que él había documentado en la cueva de Mayenne Sciences (Thorigné-en-Charnie, Mayenne, Francia) (fig. 11), una de las estaciones rupestres paleolíticas de latitud más elevada, y los que habíamos registrado en El Castillo, ambos sugerimos la posibilidad de una conexión entre estas formas y la representación esquemática del animal bisonte. Las razones que me llevan a poner sobre la mesa esta correspondencia representativa son de índole principalmente morfológica (características y comparaciones formales) y, en menor grado, técnica y topográfica. No consideramos necesario repetir los datos derivados de los distintos análisis, pero quizá conviene hacer un breve sumario de éstos:

- su forma varía de los ovales más puros a los ovales sub-triangulares (algunos muestran trazos que complementan la forma básica),

- se realizan en pigmento rojo y en ocre amarillento (pardo),

- se presentan muy frecuentemente asociados entre ellos,

- y se localizan, excepto 1 (sub-área 4.b), en la Galería de las Manos (1 en el final del sector 2.a.3 y el resto en el sector 2.b.1).

Los bisontes del Panel de las Manos (sector 2.a.1), por su parte, se caracterizan por haber sido trazados en ocre amarillento, ausencia de detallismo, formas generalmente masivas en su tren delantero y cabezas bastante indefinidas e informes (fig. 12). Algunos de ellos se hallan incompletos $(\mathrm{N}=4)$. Sus siluetas, alejadas del naturalismo, provocaron que $\mathrm{H}$. Alcalde del Río et al. (1911: 130) las considerasen dentro del grupo de pinturas rojas primitivas y que A. Leroi-Gourhan las encuadrase dentro del santuario más antiguo de El Castillo (1965: citado en 1995). El color ocre amarillento o pardo es tanto en los signos como en los zoomorfos un tipo de pintura que apenas ha sido utilizada en El Castillo. De las 27 unidades gráficas de signos plasmadas en esta técnica, 22 se hallan en el Área 2 (todas en las sub-áreas 2.a y 2.b). Su localización, por tanto, es muy precisa y puede estar poniendo de manifiesto, debido también a su infrecuencia, la sincronía de estas manifestaciones. Se observa, de igual modo, como los dos tipos de imágenes "elaboradas" que más se llevan a cabo en este color son los bisontes del Panel de las Manos y los signos ovales (en menor medida se 


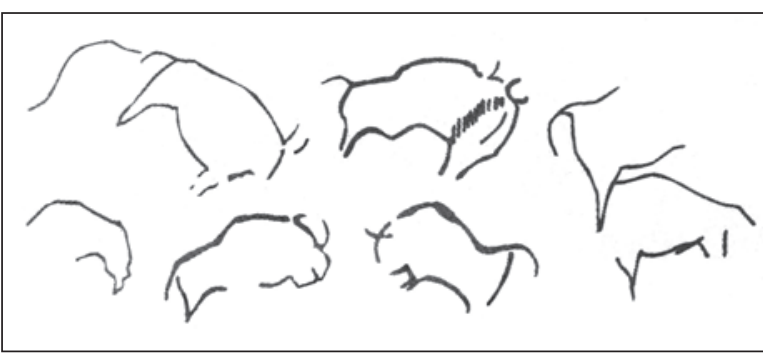

Figura 12. Siluetas de los bisontes realizados en ocre amarillento y situados en el conocido como Panel de las Manos (sector 2.a.1) (Calcos de Alcalde del Río et al, 1911).

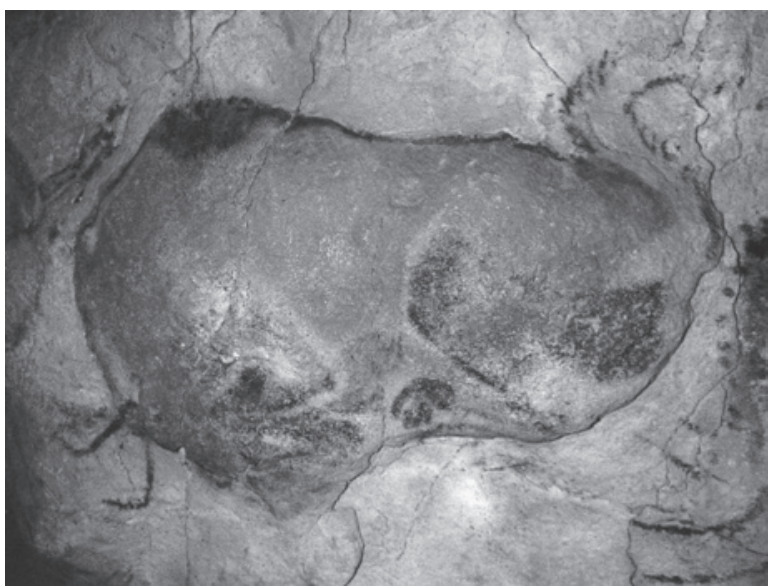

Lámina IV. Bisonte bícromo del techo de Altamira (tomada de Freeman y González

Echegaray, 2001).

perciben 3 signos rectangulares en el sector 2.a.3 y dos 2 signos circulares del sector 3.a.3). Nuestra hipótesis es que los signos ovales de El Castillo son la expresión simplificada de los bisontes que se realizaron en el $\mathrm{Pa}$ nel de las Manos.

Creemos que es probable que la base del concepto ideológico que está detrás de ambas imágenes (bisonte y oval) sea muy parecida y que en realidad esta variación formal tan solo implique una readaptación de la representación a otro espacio diferente.

La esquematización y simplificación de figuras zoomorfas dentro de un mismo horizonte crono-cultural es algo probado, incluso en la propia cavidad de El Castillo, como sucede con varios cápridos en negro y su asociación contextual con la representación de unos cuernos también de cáprido en perspectiva frontal (sub-área 3.d). La vinculación de las formas ovales con el animal bisonte es notoria también en otras cuevas. En Altamira, por ejemplo, el contorno de algunos bisontes bícromos (especialmente los realizados sobre

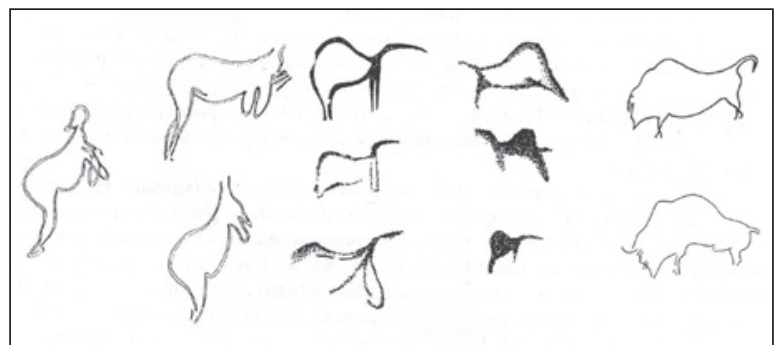

Figura 13. Secuencia de la transmutación de mujer a bisonte y viceversa que se documenta en la cueva de Pech Merle (Lot, Francia), según A. Leroi-Gourhan (tomada de Sanchidrián, 2001)

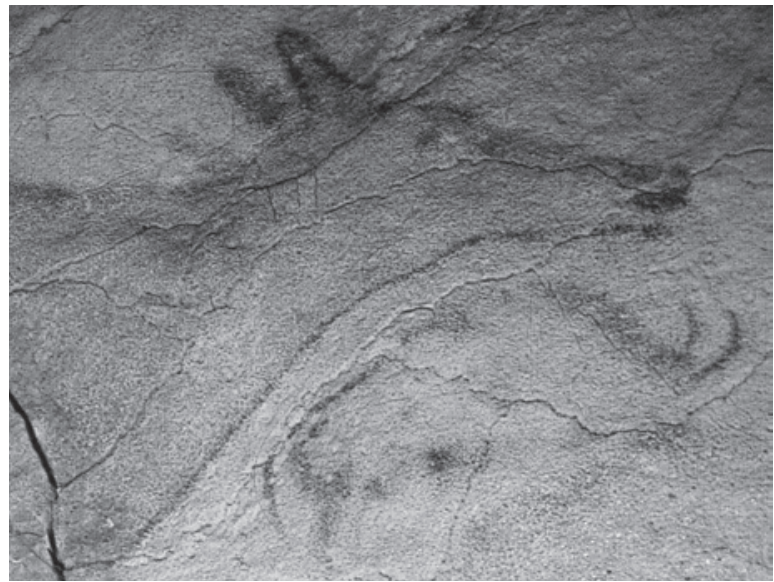

Lámina V. Bisonte esquematizado en contexto con la gran cierva del techo de Altamira (tomada de Freeman y González Echegaray, 2001).

resaltes rocosos) (Lámina IV) recuerda a esta forma geométrica. Pero, sin duda, se aprecia de una manera mucho más evidente esta relación en un bisonte de pequeño tamaño en la proximidad de la gran cierva también del techo de Altamira. Se trata de un paso intermedio en la esquematización de este animal (Lámina V). Más allá del significado y valor que otorgó A. Leroi-Gourhan al animal bisonte, es interesante comprobar como entre los estadios intermedios de la supuesta transmutación de éste en mujer (Panel de Pech Merle) se hallan algunas formas de desarrollo próximas a lo oval (fig. 13).

En la cueva de El Castillo no es la primera vez que una forma oval se liga a una posible figura de bisonte: H. Alcalde del Río et al. estimaron que una gran mancha roja de la Gran Sala (sector 1.a.2) (fig. 14), situada sobre un espacio subtriangular-ovalado delimitado por unas grietas naturales, constituía una imagen inacabada, "que figura bastante bien el cuerpo de un bisonte. Se le embadurnó de rojo y se le añadió una cola y una 


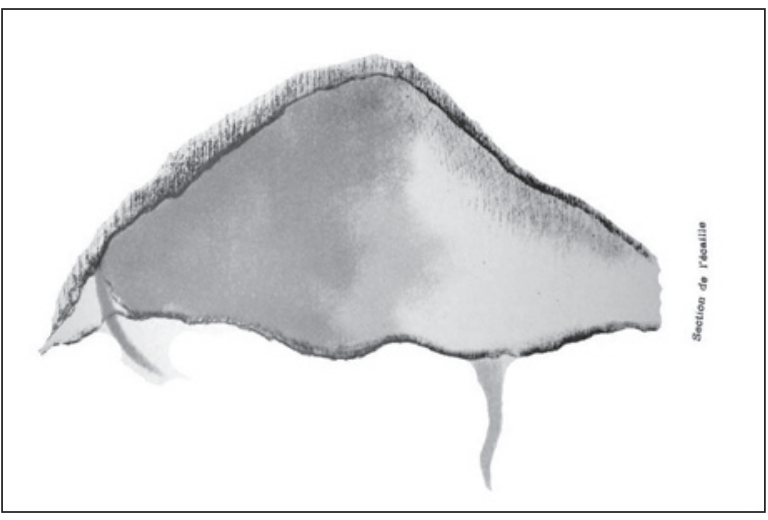

Figura 14. Supuesta figura de bisonte en color rojo que aprovecha las grietas naturales del soporte, según H. Alcalde del Río et al. (1911).

sola pata; la obra no se ha sido acabada, pero evoca, sin ningún género de duda, la comparación de las gibas del techo de Altamira sobre el que se pintaron los Bisontes polícromos" (Alcalde del Río et al. 1911: 152 - 154).

Entre los signos ovales de Mayenne Sciences, R. Pigeaud analizó uno que albergaba "una curiosa excrecencia sinuosa que recuerda mucho a la cornamenta de un bisonte" y otro que presentaba "un trazo oblicuo que termina en la proximidad de unos de los dos lados, dando aquí la impresión de un apéndice"(Pigeaud 2002 :457). En El Castillo igualmente se han documentado ovales con trazos asociados $(\mathrm{N}=3)$. En dos de ellos se repite un esquema compositivo. El signo oval en ocre amarillento (tipo 6) (muy deteriorado) presenta un trazo oblicuo en su parte superior derecha que converge con otro corto horizontal y dos trazos cortos verticales-oblicuos, uno en su parte inferior derecha y otro en su inferior izquierda (fig. 7). El signo oval en pigmento rojo (tipo 5) (fig. 6) exhibe un trazo oblicuo en su parte derecha que cruza el signo y otro más corto horizontal que converge con el anterior. Los trazos oblicuos y sus convergentes horizontales cortos constatados en estos dos signos podrían estar representando la esquematización de los cuernos, como apuntaba R. Pigeaud. Por su parte, sería plausible que los dos trazos cortos inferiores del oval tipo 6 figurasen las patas del animal. La identificación de estos trazos asociados y su disposición son otro elemento que, a nuestro juicio, contribuyen a sustentar esta hipótesis. Es llamativa la similitud formal de los signos ovales de Mayenne Sciences y de El Castillo, así como la concurrencia interpretativa que nos han transmitido a los dos investigadores que más recientemente los hemos estudiado.

\section{IMPLICACIONES CRONOLÓGICAS}

En los signos ovales apenas se constatan superposiciones, únicamente observamos como uno de ellos se superpone a una mano en negativo. Además de por su semejanza morfológica y técnica, su situación contextual apunta a un mismo momento de realización de estos signos. Dejando a un lado la posibilidad de que sean una esquematización de la figura de bisonte, como se defendió en el anterior apartado, se debe reconocer que el pigmento amarillento es escaso en la cavidad y que prácticamente se reparte entre los animales (en su gran mayoría bisontes) del Panel de las Manos (sector 2.a.1) y los signos ovales de la galería del mismo nombre (también se distinguen varios signos rectangulares en este color en el inicio de dicha galería). En nuestra opinión, es un dato a tener en cuenta para el estudio cronológico de estas manifestaciones, ya que la localización de este pigmento es muy específica (Área 2) y el tipo de imágenes abarca un rango reducido. Los rasgos de los bisontes del Panel de las Manos remiten a un estilo anterior al IV de A. Leroi-Gourhan. Numerosos investigadores que han abordado hasta el momento la problemática cronología de esta caverna como H. Alcalde del Río et al. (1911), A. Leroi-Gourhan (1995, 1965), J. González Echegaray (1972) y C. González Sainz et al. (2003) han planteado la antigüedad estilística de estas figuras, lo que inevitablemente se ha ligado a una correspondencia equivalente cronológica. J. González Echegaray apuntó a un Solutrense Superior (1972: 417), mientras que más recientemente C. González Sainz et al. (2003: 106) han señalado que el trazo lineal rojo y amarillo de contorno (con distintas formas de aplicación) corresponde a los momentos más antiguos de decoración de la cavidad (estilo III y probablemente también de estilo II). Estamos de acuerdo con estas inferencias que se ven confirmadas por las superposiciones, puesto que se advierten figuras de ciervas grabadas del período Magdaleniense Inferior (por comparación con piezas decoradas muebles) superpuestas a los animales en ocre amarillento. De modo que si vinculamos estas imágenes con los signos ovales y algunos rectángulos, estos podrían también haber sido realizados durante el Solutrense o en los momentos iniciales del Magdaleniense. Admitimos que los argumentos que enlazan las figuras de bisontes citadas con los ovales y en menor medida con los signos rectangulares en amarillo no son absolutamente contundentes pero configuran al menos una posibilidad a valorar. Una mirada a la cronología de las figuras ovales en el arte mueble reafirma las posiciones previas, a pesar de la prudencia 
que debemos tener cuando relacionamos los signos rupestres con los muebles. Según S. Corchón (1986: 183) los temas ovales se encuentran a partir del Solutrense superior - Magdaleniense inicial, aunque se prolongan a lo largo de toda la secuencia Magdaleniense. Por último, se debe hacer mención de las dos dataciones que se han obtenido en la citada cueva francesa de Mayenne Sciences procedentes de dos muestras de la figura de un caballo que ha proporcionado unas fechas de $24.220 \pm 850 \mathrm{BP}$ (Gif A 100647) y $24.900 \pm 360 \mathrm{BP}$ (Gif A 100645) (Pigeaud et al. 2003). Las figuraciones de esta cavidad han sido consideradas como un conjunto sincrónico dentro del periodo Gravetiense, relacionándose con las cuevas de Pech Merle y Cougnac (Lot-Quercy, Francia) (Pigeaud et al. 2003). Sin querer ligar directamente la antigüedad de los ovales de la cueva que ocupa nuestro estudio con aquella de Mayenne Sciences, debemos reconocer que estas fechas demuestran cuanto menos la existencia de estas formas en los principios del fenómeno expresivo pleistocénico.

\section{BIBLIOGRAFÍA}

ALCALDE DEL RÍO, H.; BREUIL, H. y SIERRA, L. (1911): Les cavernes de la Région Cantabrique. Mónaco.

BERNALDO DE QUIRÓS, F. y MINGO, A. (2005): "La interpretación de los signos", en J. A. Lasheras y J. González Echegaray (eds.), El significado del Arte Paleolítico: 211-228.

BREUIL, H. (1952): Quatre cents siecles d'art parietal. Montignac-Paris.

BREUIL, H. (1979): Four hundred centuries of cave art. Hacker Art Books. New York.

CABRERA VALDÉS, V. (1984): El yacimiento de la cueva de El Castillo (Puente Viesgo, Santander). Biblioteca Praehistorica Hispana XXII.

CAPITAN, L. y BREUIL, H. (1902): "Les gravures sur les parois des grottes préhistoriques : la grotte des Combarelles", Revue de l'Ecole d'Anthropologie de Paris $12: 33-46$.

CASADO LÓPEZ, M. P. (1977): Los signos en el arte Paleolítico de la Península Ibérica. Zaragoza.

CORCHÓN, M.S. (1986): Arte mueble paleolítico cantábrico: contexto y análisis interno. Centro de Investigación y Museo de Altamira. Monografías $\mathrm{N}^{\mathrm{o}}$ 16. Ministerio de Cultura. Madrid.

FREEMAN, L. G. y GONZÁLEZ ECHEGARAY, J. (2001): La grotte d'Altamira. Editorial Seuil / La Maison des Roches.
GONZÁLEZ ECHEGARAY, J. (1972): "Notas para el estudio cronológico del arte rupestre de la cueva de El Castillo", En Santander-Symposium: 409-422. Santander-Madrid.

GONZÁLEZ ECHEGARAY, J. y MOURE, J. A. (1970): "Figuras rupestres inéditas en la cueva de El Castillo (Puente Viesgo, Santander)", Boletín del Seminario de Arte y Arqueología XXXVI: 441-447.

GONZÁLEZ MORALES, M. R. (1994): "Pero... ¿hubo alguna vez once mil bisontes? Los temas del arte parietal paleolítico de la región cantábrica", Complutum 5: 291-302.

GONZÁlEZ SAINZ, C.; CACHO TOCA, R. y FUKAWAZA, T. (2003): Arte paleolitico en la región cantábrica. Universidad de Cantabria.

GROENEN, M. (2000): Sombra y luz en el arte paleolítico. Editorial Ariel Prehistoria. Barcelona.

GUTIÉRREZ, E. y MUÑOZ, E. (2004): Guía para conocer las cuevas del Monte Castillo. El mayor conjunto de arte paleolítico de la Región Cantábrica. Gobierno de Cantabria.

HERNANDO, A. (1999): "Percepción de la realidad y Prehistoria. Relación entre la construcción de la realidad y la complejidad socioeconómica en los grupos humanos". Trabajos de Prehistoria 2: 19-35.

HERNANDO, A. (2002): Arqueología de la identidad. Editorial AKAL Arqueología, Madrid.

LAMING-EMPERAIRE, A. (1962): La signification de l'art rupestre paléolithique. Editorial Picard. Paris.

LAYTON, R. (1987): "The use of Ethnographic Parallels in Interpreting Upper Paleolithic Rock Art", en L. Holy (ed.), Comparative Anthropology: 210239. Blackwell.

LEACH, E. (1989): Cultura y comunicación. La lógica de la conexión de los símbolos. Siglo XXI. Madrid.

LEROI-GOURHAN, A. (1958) : "Le symbolisme des grands signes dans l’art pariétal paléolithique", $\mathrm{Bu}$ lletin de la Societé Préhistorique Française LV : 307-321.

LEROI-GOURHAN, A. (1965): La Préhistoire de l'art occidental. Paris.

LEROI-GOURHAN, A. (1966): "Les signes pariétaux de Paléolithique supérieur franco-cantabrique", Simposio Internacional de arte rupestre: $67-$ 77. Barcelona.

LEROI-GOURHAN, A. (1978): "Les signes geometriques dans l’art paléolithique (France-Espagne)", Le Courrier du CNRS 27 : 9-14.

LEROI-GOURHAN, A. (1995): Préhistoire de l'art occidental. Citadelles y Mazenod. Paris. 
MAQUET, J. (1999): La experiencia estética. La mirada de un antropólogo sobre el arte. Celeste Universidad. Madrid.

MAS, M. (2005): La cueva del Tajo de Las Figuras. Colección Varia. UNED, Madrid.

MINGO, A. (2004): "The Signs in the Rock Art at Castillo Cave (Puente Viesgo Cantabria, Spain)", Actas del XIV Congreso de la UISPP (Lieja, Bélgica): 199-208.

MOURE ROMANILLO, A.; GONZÁLEZ SAINZ, C.: BERNALDO DE QUIRÓS, F. y CABRERA VALDÉS, V. (1996): "Dataciones absolutas de pigmentos en cuevas cantábricas: Altamira, El Castillo, Chimeneas, Las Monedas", en A. Moure (ed.), El hombre fósil. 80 años después: 295-324. Servicio de Publicaciones de la Universidad de Cantabria. Santander.

PIGEAUD, R. (2002) : "La grotte ornée Mayenne Sciences (Thorigné-en-Charnie, Mayenne): grottelimite aux marges du monde anté-magdalénien“, L'Anthropologie 106 : 445 - 489.

PIGEAUD, R. ; VALLADAS, H. ; ARNOLD, M. y CACHIER, H. (2003): "Deux dates carbone 14 en spectrométrie de masse par accélérateur (SMA) pour une représentation pariétale de la grotte ornée Mayenne-Sciences (Thorigné-en-Charnie, Mayenne): émergence d'un art gravettien en France septentrionale?"“, C.-R. Palevol: 161-168.
SAUVET, G. (1993) : "Les signes parietaux", en L'art pariétal paléolithique. Techniques et methods d'étude. Comité des travaux historiques et scientifiques du Ministère de l'Enseignement Supérieur et de la Recherche. Documents préhistoriques 5: 219-234.

UCKO, P. J. (1989): "La subjetividad y el estudio del arte parietal paleolítico", en M. González Morales (ed.), Cien años después de Sautuola: 283-359. Diputación Regional de Cantabria. Consejería de Cultura, Educación y Deporte, Santander.

VALLADAS, H.; CACHIER, H.; MAURICE, P.; BERNALDO DE QUIRÓS, F.; CABRERA VALDÉS, V.; UZQUIANO, P. y ARNOLD, M. (1992): "Direct radiocarbon dates for prehistoric paintings at the Altamira, El Castillo and Niaux Caves", Nature 357: 68-70. doi:10.1038/357068a0

VALLADAS, H.; TISNÉRAT-LABORDE, N.; CACHIER, H.; ARNOLD, M.; BERNALDO DE QUIRÓS, F.; CABRERA VALDÉS, V.; CLOTTES, J.; COURTIN, J.; FORTEA, J. J.; GONZÁLEZSAINZ, C. y MOURE, A. (2001): "Radiocarbon AMS dates for Paleolithic Cave Paintings", Radiocarbon 43: 977-986.

VIALOU, D. (1983) : "Les images préhistoriques", La Recherche 144, 14 : 586-597.

VIALOU,D. (1998): "Problématique de l'interpretation de l'art paléolithique", Rivista di Scienze Preistoriche XLIX : 267-281.

FECHA DE ENTRADA: 18-02-2010

FECHA DE ACEPTACIÓN: 18-01-2011 